\title{
Professor homem na educação infantil: o olhar de acadêmicos e alunos egressos do curso de pedagogia
}

Resumo: $\bigcirc$ presente estudo teve como objetivo investigar a atuação de professores homens na Educação Infantil com crianças de 0 a 3 anos, segundo a perspectiva de acadêmicos e egressos do curso de Pedagogia, sendo todos representantes do gênero masculino. A pesquisa bibliográ ca abordou questões relativas ao conceito de gênero, atuação de homens com crianças e formação docente para atuar na Educação Infantil. A pesquisa de campo, de natureza qualitativa, foi desenvolvida por meio de entrevistas semiestruturadas com 2 graduandos e 2 alunos egressos do curso de Pedagogia. Os resultados indicaram que a maioria dos homens tem a concepção de que a mulher leva mais jeito para educar crianças de 0 a 3 anos de idade. Durante a realização dos estágios curriculares os entrevistados perceberam a estranheza por parte das pessoas ao vê-los trabalhando com os bebês das turmas de maternal. Atividades relativas ao banho e higiene pessoal das crianças não foram realizadas por um dos egressos, somente os graduandos é que tiveram essa possibilidade e eles encararam a situação com naturalidade.

Palavras-chave: Gênero. Homem. Professor. Educação Infantil.

\section{Man teacher in early childhood education: the acade- mic look and students graduates of pedagogy course}

\begin{abstract}
This study aims to investigate the performance of male teachers in kindergarten with children 0-3 years old, from the perspective of academics and graduates of the Faculty of Education, and all representatives of the male gender. The literature addresses issues related to the concept of gender, eld of men with children and teacher training to work in early childhood education. The eld research, qualitative, was developed through semi-structured interviews with two graduate students and two former students of the Faculty of Education. The results indicate that most men have the idea that the woman takes more way to educate children 0-3 years old. In carrying out internships respondents perceived the strangeness for people to see them working with babies of nursery classes. Activities related to bathing and personal care of the children were not made by one of the graduates, only graduates is that they had this possibility and they faced the situation naturally.
\end{abstract}

Keywords: Gender. Man. Teacher. Childhood Education.

\footnotetext{
l Doutora em Educação pela Pontifícia Universidade Católica do Rio Grande do Sul (PUCRS). Mestre em Psicologia Social e da Personalidade pela mesma instituição. Professora Ajunta da Universidade Federal de Mato Grosso do Sul, Câmpus de Naviraí (UFMS/CPNV). Líder do Grupo de Pesquisa em Desenvolvimento, Gênero e Educação (GEPDGE). Universidade Federal de Mato Grosso do Sul, Câmpus de Naviraí (UFMS/ CPNV).E-mail: josiane.peres@hotmail.com

2 Graduada em Pedagogia pela Universidade Federal de Mato Grosso do Sul, Câmpus de Naviraí (UFMS/CPNV). Professora de Educação Infantil da Rede Municipal de Ensino de Naviraí. Universidade Federal de Mato Grosso do Sul, Câmpus de Naviraí (UFMS/CPNV).
} 


\section{Introdução}

Embora os homens tenham contribuído com o processo de educação de crianças em âmbitos familiares, nos espaços escolares não é isso o que acontece, especialmente na Educação Infantil com crianças de 0 a 3 anos, em que há a predominância de mulheres professoras. Paralelamente, percebemos que existem poucos homens estudantes ou graduados em Pedagogia, curso que se caracteriza como a base para atuação na Educação Infantil e anos iniciais do Ensino Fundamental. E entre os homens que fazem a opção por cursar Pedagogia, muitos acabam desistindo, sendo poucos os que de fato permanecem ou concluem o referido curso de graduação.

Mas por que isso acontece? Será que os homens não se identificam com essa área de atuação? E o que pensam os poucos estudantes ou egressos do curso de Pedagogia sobre a atuação de homens professores com crianças de 0 a 3 anos? Para melhor entender essa problemática é que se justifica o presente estudo, que tem por finalidade investigar as percepções sobre a atuação de professores homens na Educação Infantil com crianças de 0 a 3 anos, segundo a perspectiva de acadêmicos e egressos do curso de Pedagogia da Universidade Federal de Mato Grosso do Sul Câmpus de Naviraí (UFMS/CPNV), sendo todos representantes do gênero masculino.

A opção por este tema ocorreu pelo fato da pouca existência de professores homens lecionando para os pequenos de 0 a 3 anos no município de Naviraí, e também por observarmos que a presença masculina no curso de Pedagogia da UFMS/CPNV é relativamente pequena. Dessa forma, surgiu a necessidade de pesquisar e entender o que pensam estes homens sobre o curso de Pedagogia e sobre uma possível atuação na Educação Infantil I ( 0 a 3 anos). A investigação deste tema contribui para entender se existem resistências desses homens quanto a essa ação, podendo ainda anular alguns conceitos relativos ao homem atuar com crianças, uma vez que este recebe a mesma formação que uma mulher e pode realizar as mesmas tarefas, inclusive o ato de cuidar nos primeiros meses de vida da criança. É oportuno dizer que quanto mais se falar sobre este assunto e explicá-lo provavelmente os homens poderão se interessar mais pela área da Pedagogia, a comunidade escolar poderá aceitar com maior facilidade a atuação de homens na Educação Infantil e, consequentemente, haverá mais professores do gênero masculino atuando nessa etapa da Educação Básica.

O desenvolvimento da pesquisa ocorreu mediante estudos bibliográficos fundamentados 
em autores como Scott (1998); Louro (2012); Possas, Fulfaro e Lopes (2012); Lopes (2012); Gonçalves (2009); Sayão (2005) entre outros, além de publicações do MEC como Lei de Diretrizes e Bases (1996) e Referencial Curricular Nacional para Educação Infantil (1998)1. Também foi realizada uma pesquisa de campo de natureza qualitativa com 4 homens, sendo que dois cursavam o $3^{\circ}$ ano do curso de Pedagogia e 2 já haviam concluído, mas não atuavam na área. Os resultados são apresentados logo após a revisão da literatura, em que abordamos sobre estudos de gênero, atuação de homem com crianças e formação de profissionais para atuar na Educação Infantil.

\section{Breve estudo sobre gênero}

Para melhor compreender o tema abordado se faz necessário uma breve conceituação de gênero, pois tal conceito permeia toda a presente pesquisa e o utilizaremos para entender a atuação masculina em uma área vista como feminina. Para Scott (1998, p.75), "[...] o termo gênero é utilizado para designar as relações sociais entre os sexos [...] tornando-se uma forma de indicar construções culturais, ou seja, a concepção da sociedade do que seriam os papéis ideais de homem e mulher”.

Sabemos que desde pequenos nos é apresentado formas de como devemos nos comportar, de acordo com o nosso sexo: masculino ou feminino. Ser homem e mulher é algo que é construído dentro de nós por meio de valores familiares e culturais que vão se estabelecendo ao longo do tempo e criando formas de dominação de um para com o outro. Estas formas muitas vezes são inoportunas e excludentes. Segundo Lopes (2012, p. 173), “[...] para a organização do mundo, a cultura reproduz representações do feminino e do masculino, que passam a ser percebidas como naturais e a contribuir para a conservação das relações de dominação vigentes". Com isso, percebemos que não se trata de forças sobrenaturais e poderosas que agem na vida das pessoas dizendo o que elas têm ou não que ser ou fazer, mas sim de atos que solidificam o senso comum, pois à medida que os outros agem de uma forma, parece que o restante também tem que agir da mesma maneira.

Historicamente a sociedade assume um papel importante como formadora de opiniões, agimos de acordo com ela e temos que seguir as suas regras para sermos "bem aceitos". Esses padrões ficam evidentes nas relações de gênero em que homem e mulher precisam seguir os padrões impostos para não serem considerados excluídos.

\footnotetext{
Apesar de reconhecer que na atualidade existem críticas relacionadas ao RCNEI, no presente estudo ele foi utilizado para buscar indicações sobre a docência na educação infantil.
} 
No passado o termo gênero foi designado por feministas, segundo Scott (1998), como forma de garantir o espaço das mulheres, para que elas obtivessem apoio e que as relações de dominação deixassem de existir. No entanto, ainda hoje existe esta ideia de superioridade, tais fatos nos levam a refletir que homem e mulher não devem ser compreendidos separadamente, pois a história de um faz parte da do outro.

Ao comentar sobre gênero, Scott (1998, p. 72) esclarece:

[...] tal palavra indica a rejeição do determinismo biológico implíito em termos como 'sexo' ou 'diferença sexual'. O termo gênero enfatizava igualmente, o aspecto relacional das definições normativas da feminilidade [...] Segundo esta visão, as mulheres e os homens eram definidos em termos recíprocos e não se poderia compreender qualquer um dos sexos por meio de um estudo inteiramente separado.

Complementando esta ideia, Rabello (2013), ao também fundamentar-se nos estudos de Scott, afirma que a utilização do termo gênero desenvolve-se nas análises feministas a partir de meados da década de 1970, quando se define como uma construção social de atributos diferentes a homens e mulheres, efetivadas durante toda a vida. Muitas vezes essa construção social determina as relações entre os sexos em vários aspectos. Assim, Rabello (2013, p.911) entende que "[...] homens e mulheres são responsáveis por mudanças nas igualdades de gênero, pois as mulheres lutam para não serem subordinadas aos homens e os homens não abrem mão de reproduzirem o seu papel de dominante". Dessa forma, assumem papéis impostos pela sociedade.

Para Possas, Fulfaro e Lopes (2012, p. 192), “[...] gênero é um produto das convenções sociais que irão transformar os seres humanos no que se considera homem e mulher". Estes autores evidenciam que as ações sociais dos papéis masculinos e femininos podem influenciar os comportamentos ao ponto de adequar critérios previamente estabelecidos.

Por este viés, Lopes (2012) destaca que somos testados em nossa relação "homem" e "mulher" o tempo todo, desde quando nascemos até quando chegamos à escola. A instituição educativa deveria ser um espaço neutro, que não influenciasse as opiniões relativas à gênero ou qualquer outra relação entre os seres, mas geralmente não é assim que ocorre. Neste espaço muitas vezes são criados estereótipos que ficam nas mentes por muito tempo estabelecendo situações de preconceito, conforme salienta Lopes (2012, p. 181):

[...] a escola contribui para a reprodução e legitimação das relações de poder desiguais entre os gêneros, pois inconscientemente reforça que há um tipo de comportamento e de postura que é reservado e estimulado aos meninos, mas que, ao mesmo tempo, é vedado e coibido as meninas.

Corroborando as ideias de Lopes (2012), compreendemos que culturalmente as atitudes 
presenciadas na escola podem ser levadas para o resto de nossas vidas, por exemplo, para as meninas é cobrado que tudo esteja perfeito, que ela assuma o papel de dona de casa, pois desde pequena são levadas pelas brincadeiras a fazer atividades relacionadas ao trabalho doméstico e ao menino é cobrado que assuma a função do homem de provedor da casa. Assim desde pequenos somos condicionados a fazer tudo o que a sociedade acredita que está politicamente correto, isto implica até na decisão sobre qual profissão se deve escolher, pois se as pessoas fogem aos padrões do que está indicado pela sociedade acaba por gerar estranheza. Como exemplo de estranheza, podemos mencionar o fato de um homem atuar como docente em turmas de crianças de 0 a 3 anos, conforme apresentaremos no próximo tópico deste artigo.

\section{A atuação do homem na Educação Infantil}

A Educação Infantil foi historicamente constituída como um espaço de predominância do gênero feminino, sendo que um dos motivos refere-se ao fato de que mulheres há muitos anos serem associadas ao ato de cuidar e educar, conforme Araújo e Hammes (2012). Diante deste pensamento, tal atividade não deveria ser exercida pelo homem.

Os referidos autores ressaltam que no caso de educação de crianças maiores, ou o que atualmente é conhecido como anos iniciais do Ensino Fundamental, a realidade era diferente. Se voltarmos ao passado na época Jesuítica percebemos que os educadores eram homens e as mulheres sequer podiam frequentar as salas de aula. Dessa forma não poderiam se tornar professoras.

Assim, podemos afirmar que o Ensino Fundamental foi pensado por homens e durante muito tempo a figura masculina prevalecia nas escolas no papel de professor. Gradativamente essa realidade foi se modificando, as mulheres começaram a ocupar o mercado de trabalho, especialmente à área da educação, resultando no que ficou conhecido como processo de feminização do magistério, conforme afirmam Louro (2012) e Gonçalves (2009).

Para Louro (2012), o ingresso das mulheres como professoras no mercado de trabalho era considerado uma extensão da maternidade:

Afirmavam que as mulheres tinham, "por natureza", uma inclinação para o trato com as crianças, que elas são as primeiras e "naturais educadoras". Portanto nada mais adequado do que lhes confiar à educação dos pequenos. Se o destino primordial da mulher era a maternidade bastaria pensar que o magistério representava, de certa forma, uma "extensão da maternidade", cada aluno ou aluna vistos como filho ou filha "espiritual" (LOURO, 2012, p. 450). 
No passado havia apenas homens professores, a associação entre as habilidades femininas, principalmente relacionadas com a maternidade e a educação escolar de crianças, foram fatores que contribuíram para que gradativamente os homens se afastassem da profissão, tornando o magistério uma área de atuação mais feminina. Gonçalves (2009) ao comentar sobre o processo de feminização do magistério afirma que:

Outro fator histórico, econômico e social que influenciou na saída dos homens e na entrada das mulheres na área da educação diz respeito às representações sociais relativas à manutenção financeira do lar. No período em que as mulheres não trabalhavam fora de casa, os homens eram os provedores, responsáveis pelas obrigações do lar (GONÇALVES, 2009, p. 42).

As questões salariais continuam sendo um dos fatores que justificam a ausência de homens no trabalho escolar com crianças, conforme Gonçalves (2009). No entanto as mulheres na atualidade também contribuem com o sustento de suas famílias, inclusive as que atuam na área da educação.

Se no Ensino Fundamental a educação foi pensada e, durante muito tempo, desenvolvida por homens professores, na Educação Infantil ela foi idealizada por um homem, que indicava as mulheres como principais educadoras, de acordo com Amude e Silva (2008). Assim, Friedrich Fröebel criou o primeiro Jardim de Infância ${ }^{1}$ por entender que as crianças eram como plantas que precisava ser cultivadas e, nesse contexto, as mulheres tinham maiores aptidões para trabalhar com as crianças menores de 6 anos de idade.

Era meta do educador a formação de mulheres, chamadas de jardineiras, para que pudessem trabalhar com as crianças. Ele acreditava que as mulheres eram naturalmente dotadas de todos os pré-requisitos necessários para a realização da educação. Elas cuidavam das crianças tal qual se cuida de um jardim. Essa mulher devia ser também mãe, símbolo do afeto e do cuidado (AMUDE; SILVA, 2008, p. 170).

É interessante notar que mesmo o primeiro Jardim de Infância sendo idealizado por um homem, é a figura feminina que ele julga apta para trabalhar nesse ambiente educacional levando em conta suas relações de carinho e cuidado com as crianças. Assim, na Educação Infantil sempre houve a predominância de mulheres atuando como professoras e, nesse sentido, Gonçalves (2009) reflete:

[...] O que podemos notar é que, especialmente na Educação Infantil e anos iniciais do Ensino Fundamental, são poucos os homens que atuam como docentes. Nesta perspectiva justamente numa fase da formação humana em que é importante haver o contato da criança com homens e mulheres. Apesar de que a própria sociedade talvez não tenha tanta facilidade em aceitar muitos homens trabalhando com crianças, devido às representações predominantes de que as mulheres é que têm maiores habilidades para desenvolver o trabalho educativo (GONÇALVES, 2009, p. 13).

Também Sayão (2005) comenta que existe uma polêmica quanto ao trabalho masculino nas creches porque os cuidados e a educação das crianças vêm sendo, em grande parte das culturas, uma 
atribuição do universo feminino, carregando assim as marcas culturais da maternagem, ou seja, as marcas culturais do feminino. A autora ainda coloca que:

[...] convivemos com concepções mais ligadas ao biológico, com forte apelo à reprodução e à maternidade, ou, mesmo, em alguns casos, porque o marco teórico advém de uma perspectiva mais culturalista voltada para uma defesa política do cuidado como 'trabalho feminino' (SAYÃO, 2005, p. I52).

É importante notar que esta visão de maternagem que a autora cita está fortemente ligada às representações de gênero onde a mulher por estar habituada a serviços domésticos e ao cuidado com as crianças, pode também desenvolver o mesmo papel nas salas de aula.

Gonçalves (2009) aponta que um dos motivos para a falta de interesse masculino na Educação Infantil está relacionado ao fato de a remuneração salarial ser pouca para uma pessoa que precisa sustentar a família. Dessa forma, Gonçalves (2009) salienta que se de alguma forma o homem tenha a pretensão de estar em uma posição privilegiada assumindo na escola cargo de coordenador ou de gestor que ao passo que lhe proporciona status lhe rende salário melhor do que da atuação com professor da Educação Infantil.

Quanto às possíveis implicações relativas ao trabalho de professores homens na Educação Infantil, Sayão (2005) relata que existem diferentes percepções sobre a atuação do homem na Educação Infantil, que pode ser vista sob o olhar da Psicologia em que os homens iriam suprir a carência das crianças que têm a mãe como chefe de família. Ainda sob este olhar, a autora enfatiza que esta atuação pode ser pautada na sociologia do trabalho, por meio do aumento de homens atuando nesta área estariam desmistificando que esta profissão seria somente feminina.

Podemos dizer que este modelo de atuação poderá ser desmistificado quando conseguirmos deixar de lado algumas ideias pré-concebidas sobre a atuação do homem com o cuidado e a educação de crianças de até três anos de idade. Quanto a isso Sayão (2005) pondera sobre as crenças que as pessoas têm sobre a atuação masculina no âmbito da educação infantil ressaltando que:

É indubitável a crença disseminada de um homem sexuado, ativo, perverso e que deve ficar distante do corpo das crianças. Em contrapartida, há formas explíitas de conceber as mulheres como assexuadas e puras e, portanto, ideais para este tipo de trabalho. No entanto, além de nossas crenças mais comuns e, muitas vezes pré-concebidas, o que sabemos sobre como atuam professores em creches? ( SAYÃO, 2005, p.16)

A pergunta da autora se torna relevante, pois não sabemos de fato quem é esse homem que está disposto a enfrentar o julgamento muitas vezes malévolo da sociedade para conseguir um espaço dentro desse mundo tão voltado para as mulheres, onde é necessário que ele sempre se afirme 
como um bom profissional. Percebemos que a sociedade ainda tem receio da atuação do homem com bebês, talvez até os julguem incapazes de cuidar de crianças fazendo com que o homem não se interesse em trilhar os caminhos da docência na Educação Infantil.

Em contrapartida, sabemos que a sociedade também é dinâmica e temos presenciado cada vez mais a participação dos homens contribuindo com as tarefas domésticas, inclusive com a educação dos filhos. Nesse sentido, Gonçalves (2009, p. 29) sinaliza:

Como os estereótipos vão se modificando, as representações acerca dos espaços em que homens e mulheres deveriam atuar foram sendo alteradas. É bem verdade que as questões ligadas ao poder ainda são mais associadas aos homens, mas também é verdade que, atualmente, eles têm participado mais intensamente do processo de educação dos filhos, se comparados com épocas não muito remotas (GONÇALVES, 2009, p.29).

Se em casa os homens são considerados educadores, na escola eles também poderiam muito contribuir com o processo de educação de crianças, sendo preciso desmitificar a ideia de que não há espaço para o homem atuar como docente de Educação Infantil. O importante é a formação para essa atuação e não apenas o fato de pertencer ao gênero feminino ou masculino.

Para entender a importância da formação, no trabalho da Educação Infantil com crianças de 0 a 3 anos, no próximo tópico deste artigo abordaremos questões sobre o cuidar e educar e também o que algumas publicações do MEC sinalizam sobre a atuação do profissional masculino na atuação com bebês.

\section{Formação de professores homens para atuar na Educação Infan- til: Contribuições da LDB e RCNEI}

Para melhor compreensão da Lei de Diretrizes e Bases da Educação (LDB) se faz necessário realizar um rápido apanhado sobre as relações de cuidar e educar crianças de 0 a 3 anos que precisam de atenção e cuidado integral. Sayão (2005) ressalta que a partir de sua implantação, a Educação Infantil assumiu a dupla função de cuidar e educar crianças pequenas. Assim, a "[...] pré-escola seria o lugar do aprendizado que prepararia as crianças para vida escolar e a creche seria um lugar de acolhimento, de guarda para as crianças menores" (SAYÃO, 2005, p.156).

Montenegro (2005) entende que existe uma tensão entre o assistencialismo e a educação, fato este histórico, que marcou a trajetória da Educação Infantil no Brasil constituindo-se a separação do cuidado, da educação nas creches. Por outro lado, em Brasil (1998) podemos observar que cuidado 
e educação caminham juntos e o cuidar exige uma ampla junção de conhecimentos, que valorizem e auxiliem a criança em seu desenvolvimento. Assim, para cuidar é preciso estar comprometido com o outro, estabelecer vínculo com a criança ganhar a sua confiança, ensiná-la a reconhecer as suas necessidades, dar atenção se interessar por aquilo que elas gostam para então promover a autonomia na criança. (BRASIL, 1998)

Conforme a LDB, toda criança desde o seu nascimento tem direito a frequentar a escola. Na primeira fase de desenvolvimento as crianças de 0 a 3 anos são atendidas em creches ou Centro Integrado de Educação Infantil, e garantem o desenvolvimento integral das crianças atendidas.

Art. 29०. A educação infantil, primeira etapa da educação básica, tem como finalidade o desenvolvimento integral da criança até seis anos de idade, em seus aspectos físico, psicológico, intelectual e social, complementando a ação da família e da comunidade. (BRASIL, 1996, p. 12)

Pensando no desenvolvimento integral da criança é que se faz necessário entender que a LDB não traz nenhuma objeção à atuação de homens, o que diz a lei é que é necessário ter formação superior ou magistério, não mencionando nada sobre o sexo das pessoas que devem atuar com as crianças.

Art. 62․ A formação de docentes para atuar na educação básica far-se-á em nível superior, em curso de licenciatura, de graduação plena, em universidades e institutos superiores de educação, admitida, como formação mínima para o exercício do magistério na educação infantil e nas quatro primeiras séries do ensino fundamental, a oferecida em nível médio, na modalidade Normal (BRASIL, 1996, p.22).

Se o próprio documento que dispõem sobre a educação brasileira não faz nenhuma ressalva à atuação de homens na Educação Infantil, isso quer dizer que não se encontra objeção nenhuma para a participação desses homens, desde que sejam habilitados para esta função. Em consonância com LDB, o RCNEI também aborda a questão da formação e da preparação dos professores da Educação Infantil, não colocando em questão se o professor é o homem ou mulher. Dessa forma, o profissional precisa ser polivalente, capaz de ensinar e aprender e também de refletir suas práticas sempre que necessário.

Podemos constatar que as publicações do MEC não trazem nada que restrinja a atuação masculina com o cuidado com crianças de até 3 anos de idade. Pelo contrário, ressalta a importância de uma boa formação e da atenção que pode ser dada á criança durante este período para que realmente a ela seja garantido um bom desenvolvimento, independente de ser homem ou mulher o profissional que irá atuar com as mesmas.

Percebemos que o magistério vem sofrendo mudanças significativas ao longo da história, 
pois no início foi idealizado e praticado por homens, sem a mulher ter direito algum principalmente o de frequentar a escola. Logo após é ofertado o direito das mulheres de frequentar escolas e serem professoras, utilizando assim seus atributos femininos para a educação escolar de crianças. Este modelo continua presente nos dias atuais, principalmente quando se trata da Educação Infantil, sendo entendido como "natural" haver a predominância de mulheres professoras nesta etapa da Educação Básica. Porém, tal realidade é resultado de um desenvolvimento cultural, que colaborou com o interesse de investigar sobre atuação de professores do sexo masculino com crianças de 0 a 3 anos de idade, uma vez que se constata a inexistência de homens atuando como professores de Educação infantil.

\section{Metodologia da pesquisa}

Para realização do presente estudo utilizamos primeiramente a pesquisa bibliográfica norteada especialmente por Scott (1998); Louro (2012); Possas, Fulfaro e Lopes (2012); Lopes (2012); Gonçalves (2009); Sayão (2005) entre outros, além de algumas publicações do MEC como LDB e RCNEI (BRASIL, 1996 e 1998). Tais estudos servem de base para contextualizar o tema e realizar a devida análise dos dados. Segundo Gressler (2007, p.73) “[...] toda pesquisa implica o levantamento de informações de variadas fontes: livros, revistas, publicações avulsas, mapas, internet, independente dos métodos e das técnicas empregados".

Em seguida, realizamos uma pesquisa de campo de natureza qualitativa, que na visão de Gressler (2007, p.98) “[...] a pesquisa qualitativa é fundamentalmente interpretativa. Interpretação dos resultados desponta como a totalidade de uma especulação que tem com base a descrição de um fenômeno em um contexto.” Realizamos a coleta de dados no município de Naviraí MS, com 4 homens, sendo que 2 estavam cursando Pedagogia na UFMS/CPNV e realizavam o primeiro estágio curricular supervisionado que o curso propõe e acontece na Educação Infantil. Os outros 2 eram alunos egressos deste mesmo curso de licenciatura e já passaram por todos os processos que o curso exige, possuindo um olhar diferente dos acadêmicos que ainda estavam no primeiro estágio.

Esta escolha se deu pelo motivo de não haver professores homens atuando na Educação Infantil no município de Naviraí, por esta razão optamos por saber o que pensava os acadêmicos que realizariam o primeiro estágio curricular do curso de Pedagogia com as turmas de 0 a 3 anos e 
o que os egressos deste mesmo curso tinham a dizer sobre a participação de homens nesta fase da educação, visto já terem passado por todas as etapas de ensino, inclusive do estágio curricular.

Para a escolha dos entrevistados utilizamos dois critérios: era necessário estar cursando ou já ter cursado Pedagogia na Universidade Federal do Mato Grosso do Sul campus de Naviraí, e no caso de quem ainda estava cursando deveria estar realizando o primeiro estágio supervisionado que o curso oferece. Segundo as análises de Alves-Mazzotti e Gewandsznajder (1999 p.162) “[...] os participantes são escolhidos propositalmente pensando as questões norteadoras da pesquisa, e a disponibilidade dos sujeitos envolvidos”. Escolher os participantes não é uma situação fácil é possível que o pesquisador não consiga indicar todos em seu projeto, mas é importante que ele escolha pelo menos alguns para o complemento de sua pesquisa.

Dando seguimento ao instrumento utilizado para a realização da pesquisa, fizemos a opção por utilizar entrevistas semiestruturadas. Ainda sob o olhar de Gressler (2007 p.179) “[...] a entrevista semiestruturada é construída em torno de um corpo de questões do qual o entrevistador parte de uma exploração em profundidade.” Para realização da entrevista foi feito contato, explicando sobre os objetivos da pesquisa e agendado horário, conforme disponibilidade dos entrevistados. Sendo que uma foi realizada na própria universidade, duas nos respectivos empregos dos entrevistados e outra na casa de um deles.Para melhor contemplar o perfil dos quatro participantes da pesquisa elaboramos um quadro que sistematiza todas as informações relevantes coletadas por meio de entrevista semiestruturada, mantendo preservada a identidade dos envolvidos, sendo utilizados nomes fictícios.

QUADRO I - Perfil dos Entrevistados Fonte: Autora (2015).

\begin{tabular}{|l|c|c|c|l|l|}
\hline Nome & Idade & $\begin{array}{c}\text { Pedagogia } \\
\text { em } \\
\text { Andamento }\end{array}$ & $\begin{array}{c}\text { Pedagogia } \\
\text { (ano que } \\
\text { concluiu) }\end{array}$ & $\begin{array}{l}\text { Área de Atuação } \\
\text { Profissional }\end{array}$ & $\begin{array}{l}\text { Configuração } \\
\text { Familiar }\end{array}$ \\
\hline Bebeto & 31 & $3^{\circ}$ Ano & - & $\begin{array}{l}\text { Funcionário Publico } \\
\text { Agente Comunitário } \\
\text { de Saúde) }\end{array}$ & $\begin{array}{l}\text { Esposa, sem } \\
\text { filhos. Esposa } \\
\text { estagiária em } \\
\text { CIEI }\end{array}$ \\
\hline Neymar & 19 & $3^{0}$ Ano & - & $\begin{array}{l}\text { Estudante (Bolsista de } \\
\text { Iniciação Cientifica) }\end{array}$ & $\begin{array}{l}\text { Solteiro, mora } \\
\text { com a mãe. }\end{array}$ \\
\hline Romário & 37 & - & 2013 & Eletricista & $\begin{array}{l}\text { Esposa e dois } \\
\text { filhos }\end{array}$ \\
\hline Sócrates & 53 & - & 2013 & $\begin{array}{l}\text { Funcionário Público } \\
\text { Auxiliar } \\
\text { Administrativo em } \\
\text { escola.) }\end{array}$ & $\begin{array}{l}\text { Esposa } \\
\text { Funcionária } \\
\text { Publica }\end{array}$ \\
\hline
\end{tabular}


Com a apresentação das informações contidas no quadro podemos perceber que os participantes possuem entre 19 e 53 anos de idade, 2 deles estavam cursando o $3^{\circ}$ ano de Pedagogia e já tiveram a oportunidade de desenvolver o estágio curricular na Educação Infantil. Os outros 2 eram egressos do curso de Pedagogia e passaram por todas as etapas exigidas pelo currículo, ou seja desenvolveram estágio curricular em anos iniciais do Ensino Fundamental e Trabalho e Educação.

Quanto à atuação profissional nenhum dos participantes atuava em escolas como professor ou estagiário. Entre os que concluíram o curso de Pedagogia, nenhum estava atuando na área, não por falta de oportunidade, mas por questões ligadas ao baixo salário que segundo um deles seria pouco para sustentar a família. Ele entendia que para começar a lecionar só se fosse como renda complementar no período noturno. No entanto, Novaes (1995) chama a atenção para o fato da remuneração salarial do professor não ser tão baixa, pois observamos homens atuando em outros setores, como escritórios, por exemplo, e ganham salários inferiores ao de professor.

Os dados coletados por meio das entrevistas semiestruturadas, foram transcritos, sistematizados e analisados, constituindo os resultados que serão apresentados na sequência.

\section{Resultados e discussão}

Para organização e discussão dos resultados, mantivemos a seguinte organização: apresentamos os dados obtidos por meio de entrevista semiestruturada, sendo selecionadas as questões que continham informações relevantes, compatíveis com o objetivo deste estudo. A discussão dos resultados ocorre de forma intercalada com as respostas dos participantes, sendo relacionado com autores que estudam a temática.

\section{Escolha da graduação, visão sobre o curso de Pedagogia e atua- ção com crianças de 0 a 3 anos}

Ao comentar sobre os motivos que levaram esses homens a se graduar em Pedagogia, os respondentes foram unânimes em dizer que este seria a $2^{a}$ opção e que começaram a cursar por não ter conseguido entrar em outros cursos de graduação, que também eram de licenciatura. Assim eles relataram: 
Na verdade a Pedagogia, como todos dizem ao entrar no curso né..., a Pedagogia me escolheu de certa forma né! Num primeiro momento eu pensava em fazer Matemática, mas eu optei pela segunda opção: a Pedagogia (BEBETO).

Então é... Eu meio que não escolhi ou fui induzido fazer Pedagogia porque era a única coisa que eu poderia fazer. Eu queria fazer Letras, mas não podia fazer aqui em Naviraí (NEYMAR).

Olha na verdade não foi uma escolha, foi uma falta de opção. Na época eu me inscrevi em Pedagogia, aí com o pessoal comentando que seria curso de mulher, eu tentei mudar pra Ciências Sociais, mas não consegui (ROMÁRIO).

Olha na verdade, não foi, nem como se diz, uma escolha. Eu sempre tive vontade de fazer um curso superior, mas na verdade seriam em outras áreas. Quando surgiu a Universidade Federal que veio pra cá e só tinha duas opções Pedagogia e Ciências Sociais, daí eu optei por Pedagogia (SÓCRATES).

Podemos perceber por meio das respostas que um queria fazer Letras (Neymar) e fazer Matemática (Romário) por gostar da área de cálculo e Educação Física (Sócrates), porém não tiveram condições e acabaram fazendo Pedagogia na Universidade Federal. É interessante notar que todos tinham a intenção de fazer um curso de licenciatura, evidenciando que já tinham o interesse em se tornar professor, porém de alunos maiores, uma vez que as referidas áreas, como Matemática, Letras e Educação Física, formam professores para atuar em outros níveis de ensino.

Em um estudo realizado por Martins (2009), em que buscou analisar os caminhos da formação de alunas do curso de Pedagogia de uma Universidade Confessional e comunitária do Rio de Janeiro, tendo como intuito entender os motivos que levaram as alunas a escolher o referido curso, foi constatado que as mulheres pesquisadas também o escolheram por $2^{\mathrm{a}}$ opção. Os resultados indicam que fatores como casamento, maternidade, não ingresso no curso pretendido, falta de dinheiro para fazer outro curso, possibilidade de emprego, entre outros, são os principais motivos que justificam a escolha por licenciatura em Pedagogia. Se as mulheres pesquisadas por Martins (2009) não demonstram tanto interesse pelo curso, os homens que em geral preferem trabalhar com crianças maiores é que acabam entrando apenas por não ter conseguido o curso de graduação pretendido.

Contudo, um fator que pode ser considerado relevante é o fato de que os homens que continuam e finalizam o curso de Pedagogia acabam tendo uma visão positiva e se dizem satisfeitos com a área. Os entrevistados desse estudo alegaram que não se arrependeram da escolha feita, pois aprenderam a gostar do curso e contribuíram para amenizar alguns rótulos que se as pessoas costumam colocar quando um homem escolhe ser professor. Assim, eles pontuaram sobre a visão que 
tinham antes de iniciar o curso de Pedagogia, comparando com a visão atual:

Eu não sabia direito pra que ou qual era a atividade do pedagogo quando se formar. Era bem limitado da minha visão (NEYMAR).

Olha anteriormente eu não tinha nem uma visão assim sobre o que era a Pedagogia. Eu ouvia falar 'Pedagogia... Pedagogia... '. Mas do que se tratava... Não sabia (BEBETO).

Antes de entrar no curso é que não tinha ideia nenhuma do que fazia a Pedagogia, sabia que pedagogo dava aula pra criança, mas não tinha ideia do que fazia na sala, do que um pedagogo fazia, as atribuições de um pedagogo... (ROMÁRIO).

O fato de estar na educação, é claro como assistente administrativo, você acaba pegando alguma coisa [...] é logico que não é como frequentar a sala de aula no dia a dia, mas posso dizer que já tinha uma noção (SÓCRATES).

Os dados evidenciam que entre os entrevistados três iniciaram o curso de Pedagogia sem ter clareza sobre a formação, apenas um é que tinha noção por já atuar em âmbito escolar. Talvez seja esse um dos motivos que justificam a desistência de homens no referido curso de graduação, o fato de não saberem certo sobre a formação e posterior área de atuação. Alguns, conforme os entrevistados, mesmo obtendo esse conhecimento durante o processo de formação profissional, permanecem até o fim e passam a se identificar com a área de formação acadêmica.

Ao comentar sobre o que pensam sobre a possibilidade e homens professores trabalhar com crianças de 0 a 3 anos, os participantes divergem em suas opiniões. O Bebeto assim enfatiza:

Para os homens atuar dentro da educação na creche é um momento de suma importância para o momento afetivo da criança, por que eu vejo muito criança ali com falta de afetividade, quando eu fiz o estágio muitas me chamavam assim 'pai', 'papai'. Então eu vejo assim a carência e também assim fica um ambiente neutro né não beneficiando só um lado.

O Neymar não vê diferenças em relação ao sexo, ficando claro em sua fala:

Eu penso que profissional deve ser preparado pra realizar o tipo de atividade que ele planejar. Eu acho que ele deve planejar bem essas atividades, definir os objetivos... Acho que ele deve desenvolver o trabalho profissional pra o qual ele foi preparado na graduação e na sua formação e não acho que diferencia o fato de ser homem ou mulher a boa execução desse trabalho.

O Referencial Curricular Nacional para Educação Infantil (BRASIL, 1998) aborda a questão de como deve ser o trabalho e o perfil de pessoas que se propõe a trabalhar com crianças pequenas sendo ele homem ou mulher. Dessa forma destaca que:

O trabalho direto com crianças pequenas exige que o professor tenha uma competência polivalente. Ser polivalente significa que ao professor cabe trabalhar com conteúdos de naturezas diversas que abrangem desde cuidados básicos essenciais até conhecimentos específicos provenientes das diversas áreas do conhecimento (BRASIL, 1998, p.4I). 
Com outro olhar Romário admite que são poucos os profissionais que atuam na área, ele afirma que a sociedade precisa aceitar o homem na Educação Infantil, pois as pessoas ainda se chocam quando veem um homem cuidando e educando as crianças, isto fica evidente em sua fala: "O meu pensamento é o seguinte, que hoje em dia tem pouco profissional que na verdade aqui você não encontra quase nenhum e eu já vi relatos, já vi publicação de lugares que têm e dá muito certo, quando a comunidade aceita essas pessoas". E ainda comentou que durante o estágio no berçário as mães ficavam surpresas com a presença dele e paravam para olhar o que ele estava fazendo. Elas ficavam a observar e não falavam nada, mas quando saiam de perto dele perguntavam para outras funcionárias: “O que ele faz aqui?” Neste sentido Araújo e Hammes (2012, p.16) chamam a atenção para a "[...] visão de que a creche é uma instituição onde apenas mulheres deveriam trabalhar. Por essa razão é vista com estranheza a presença de homens atuando como educadores ou assistentes pedagógicos".

Sócrates por sua vez, pôde perceber no estágio curricular supervisionado que ainda há algumas barreiras sobre a atuação na creche, isso fica claro quando ele comenta que as pessoas consideram estranha a presença de homens cuidando de criança e que assim como na instituição de Romário, ficaram se perguntando o que esses homens fariam ali. Quando nos referimos a homens nesta fala é porque o estágio foi em dupla e Sócrates realizou juntamente com outro homem. É importante colocar que em um de seus relatos Sócrates pontuou que para a Educação Infantil as mulheres levam mais jeito, mas que a experiência do estágio no berçário e maternal para a sua vida acadêmica foi muito relevante.

O que compreendemos mediante aos quatro relatos é que, os 2 homens que estão cursando Pedagogia, não pontuam diferenças de atuação no trabalho masculino para o feminino com crianças da Educação Infantil I. Porém, os 2 egressos que eram das primeiras turmas da UFMS/CPNV demonstram que lidaram mais com o julgamento e a estranheza das pessoas, do que os dois que realizaram o estágio recentemente.

Para Araújo e Hammes (2012), esta estranheza pode ter acontecido pois existe ainda um grande preconceito sobre a atuação do homem na Educação Infantil, pois além deles arcarem com o estereótipo de que cuidar de criança é coisa de mulher ainda sofrem retaliações por parte de alguns pais que ficam receosos em deixar suas crianças aos cuidados de um homem. 
Acreditamos que a diferença entre eles se de pelo fato do quadro de professores dos egressos ter sido feminino, já o para os que cursam possuem um quadro misto de professores inclusive o orientador de estágio na educação é homem o que colabora na desconstrução de alguns mitos.

\section{Experiências vividas no estágio e possibilidade de escolher a Edu- cação Infantil para trabalhar}

Quanto às experiências vividas no estágio curricular, Bebeto garantiu ter estabelecido uma boa relação com o Centro Integrado de Educação Infantil (CIEI) que o recebeu, dizendo ainda que, as professoras o elogiaram e ficaram curiosas para saber se ele estava gostando do curso e se havia gostado do estágio. Assim ele afirmou: "Eu respondi que estava gostando do curso, que gostei da experiência que foi muito proveitosa mesmo! Muito importante!" O fato de quase não haver homens atuando na Educação Infantil, desperta a curiosidade das mulheres que trabalham neste ambiente e nas pessoas que ali frequentam, fazendo com que elas se sintam encorajadas a perguntar o que leva ele a escolher um curso que relativamente possui mais mulheres do que homens. Neste sentido Sayão (2002) evidencia que:

No caso brasileiro, apesar de numericamente ser insignificante o número de professores do sexo masculino atuando nestas instituições, sua presença, dada às especificidades que o trabalho com as crianças pequenas suscita, é motivo de estranhamento por parte não só das mulheres profissionais de creches, como também das famílias das crianças que freqüentam estas instituiç̧ões (SAYÃO, 2002, p. 2).

Bebeto ainda colocou que não houve estranheza das mães que levavam os filhos e deixavam aos seus cuidados. Segundo ele em relato a entrevista somente uma mãe que disse que talvez a filha não fosse se acostumar com ele ali por quase não frequentar o CIEI, mas logo a menina se adaptou com a sua presença. O desenvolvimento das atividades foi o que o deixou apreensivo, contou com a ajuda da esposa, sua parceira no estágio curricular para desempenhar algumas tarefas como dar comida para várias crianças, participar da hora do banho, dessa forma conseguiu desenvolver tranquilamente as atividades pedagógicas, brincando, ensinando e aprendendo junto com as crianças que o trataram com muito carinho, o que o fez sentir-se realizado, pois nunca havia entrado em uma creche.

Já Neymar começa a conversa falando do curso de Pedagogia que teve a preocupação de procurar CIEIs que aceitassem a presença masculina em seu espaço. Assim a relação com as coor- 
denadoras foi bem tranquila, pois o receberam muito bem e deram todo o apoio que era necessário. Ao falar da experiência com as famílias ele percebeu que as mães estranhavam um pouco a sua presença ali, mas não era nada fora do comum. Ao comentar sobre as crianças ele revela que no início do curso não gostava muito de crianças, mas com o passar do tempo foi passando a gostar devido ter adquirido mais conhecimentos sobre esses pequenos seres humanos.

Com o passar do curso eu fui tendo contato com os textos ou em contato com as discussões eu fui me tornado mais paciente ou vendo que eu poderia estabelecer uma relação com as crianças, por que antes do curso eu pensava não isso nunca vai dar certo né, então eu fui vendo que é a forma de conversar com as crianças de preparar algumas atividades que elas gostem e por causa disso vão gostar de mim (NEYMAR).

Tanto homens quanto mulheres precisam possuir interesse pela criança, conhecer o seu mundo, respeitá-la, assim o estágio é um momento em que tentamos nos colocar em seus lugares, e fazer tudo pensando nelas para se ganhar a confiança, e consequentemente, a participação nas aulas principalmente com os pequenos que se dispersam facilmente.

Neymar teve a possibilidade de realizar as mesmas atividades que uma estagiária do sexo feminino, sendo tal experiência importante para o estudante de Pedagogia: "Pude fazer todas as atividades que as meninas fizeram... Houve por parte das professoras e das estagiárias um estranhamento inicial. Uma estagiária, por exemplo, achou que eu não daria banho nem nada, mas no primeiro dia eu já fui dando banho...” Diante deste fato Araújo e Hammes (2012, p.8) manifestam a ideia de que as "[...] pessoas consideram que um homem não seja capaz de dar banho, trocar fraldas, dar comida, fazer dormir, entre outras atribuições exigidas quando se trata dos cuidados oferecidos a uma criança”. Em contrapartida as experiências dos estagiários evidenciam que é possível sim que o homem realize tarefas referentes ao cuidado pessoal da criança, talvez precise de ajuda sim para iniciar, mas todo início é complicado e sempre precisamos de algum auxílio.

Quanto às experiências de Romário, ele não relatou ter dificuldades com a relação à escola, visto que ele foi muito bem recebido pela equipe. Os pais é que também estranhavam o fato de um homem estar trabalhando com crianças. Quanto ao desenvolvimento das atividades previstas no estágio, ele não apresentou dificuldade em realizar, porém ele não deu banho nas meninas, porém quando solicitado ajudava com os meninos justificando que:

Como tinha bastante estagiaria, não tinha porque eu dar banho em menino e menina. Era uma questão de lógica, não era só uma questão de querer, era uma questão de lógica porque tinham três meninas e a professora. Então não tinha porque eu ir lá no banheiro e dar banho. Então isso não significa que eu fui barrado na escola (ROMÁRIO). 
Essas relações de cuidado com a higiene na Educação Infantil, principalmente a hora do banho, são polêmicas, nos remetendo novamente as questões de gênero que são culturais, em que o homem se sente superior à mulher e por uma questão de 'lógica' como foi dito por nosso entrevistado, sente-se mal por dar banho em uma criança, que não possui nenhuma malicia, na presença de outras mulheres. Neste sentido, Sayão (2005) enfatiza que o cuidado é visto como uma atividade estabelecida pela sociedade, por meio de uma ação relacional que não envolve capacidades inatas, mas sim fatores essenciais às relações culturais que se formam com o cuidado na trajetória das diferentes experiências tanto masculinas como femininas.

Romário também expôs a sua satisfação quanto às crianças, já que pode perceber a evolução delas com o que ele se propôs a ensinar. Ele ressalta que um ponto negativo da Educação Infantil seria a falta de recurso para trabalhar e a falta de espaço, uma vez que são muitas crianças para um ambiente relativamente pequeno, ou seja, nenhum problema relacionado ao gênero do professor.

Para Sócrates as experiências do estágio curricular na Educação Infantil, a princípio foram inquietantes porque não sabiam o que estavam por vir, se sentiu apreensivo, quanto a reação dos pais das crianças, que assim como aconteceu com os outros três entrevistados, a atitude dos mesmos foi de surpresa ao chegar no CIEI e se deparar com um homem recepcionando seus filhos. Mas a inquietação do começo deu lugar a confiança depois da boa recepção das coordenadoras e demais funcionárias. Sócrates declara que o ponto que se sentiu mais apreensivo foi na hora de dar o banho assim observamos em sua fala: "O banho era justamente o ponto em que se fica mais apreensivo".

O que nos chama a atenção é o fato de que nos relatos dos 4 entrevistados, a figura dos pais com o olhar de estranheza foi unânime. Embora os estágios tenham sido realizados em épocas diferentes e em lugares diferentes a atitude foi à mesma. É comum haver estranhamentos por parte dos pais e participantes da escola afinal fomos criados para aceitar a mulher cuidando e educando a criança e quando nos deparamos com um homem nesta função nos causa impacto, pois se fossemos acostumados desde pequenos a tais práticas tudo seria diferente, saberíamos como lidar com essas situações e não agiríamos de forma certamente preconceituosa sobre a atuação da figura masculina no magistério da Educação Infantil.

Quando indagados sobre a possibilidade de escolher em que nível trabalhar somente o Bebeto escolheria atuar na Educação Infantil de 0 a 3 anos, pois se identificou e alega ainda não conhe- 
cer os outros níveis. Neymar afirma que não descartaria a possibilidade de trabalhar, mas se pudesse escolher optaria pelo Ensino Fundamental porque, segundo ele, a Educação Infantil é cansativa e exige muito planejamento. Este desejo fica nítido neste relato: “Eu ficava só meio período, pude observar isso que é um trabalho que exige bastante planejamento, mesmo que isso não seja observado sempre se eu pudesse então escolher, eu escolheria o $1^{\circ}$ ano do Ensino Fundamental". O Romário diz que: "Se fosse para escolher, escolheria o Ensino Fundamental", sendo que a justificativa para esta resposta refere-se a falta de recursos que presenciou na Educação Infantil.

Sócrates, por sua vez, preferiria atuar com a pré-escola, ou como Educação de Jovens e Adultos (EJA), mas com os bebês não, justificando que: "Os pequenininhos têm que ser das mulheres, talvez... Eu não sei... Porque eu me identifiquei com os maiorzinhos, assim.... não pelo lado financeiro, mas só por conta do cuidar mesmo."

A ideia de que a mulher é que deve atuar na Educação infantil, seguindo seus "instintos" maternos e suas habilidades de cuidar da casa ainda é muito forte e podemos percebê-la na fala de alguns entrevistados. No entanto, Carvalho (1998) em sua tese de doutorado relata que desde no início do século XX as mulheres ocupam esse espaço, pois possuem as seguintes características:

Ao longo das primeiras décadas do século $X X$, já se encontra a hegemonia de um discurso que associa o ensino primário com características consideradas femininas, tais como o amor as crianças, a abnegação e a delicadeza, e que relaciona cada vez mais enfaticamente a docência e a maternidade (CARVALHO, 1998, p.2).

Diante do que foi exposto existe uma possível falta de interesse desses homens por trabalhar na Educação Infantil, quando apenas um se diz disposto a enfrentar o que eles mesmos intitulam de desafio, porque cuidar e educar não são considerados tarefas fáceis, exigindo muita paciência, planejamento e até mesmo, como diz Bebeto, esforço físico.

Neste sentido, os egressos foram solicitados a comparar os estágios na Educação Infantil, com Ensino Fundamental e estágio em ambiente não escolar. Romário, diz a que a diferença é só o brincar e ressalta que os pequenos obedecem mais que os maiores do Ensino Fundamental e que se ele atuasse escolheria este nível para trabalhar. Sócrates relata que a experiência no Ensino Fundamental não deixou saudades, mas não trabalharia na Educação Infantil por razão de que os cuidados para com a criança precisam ser redobrados.

Para finalizar observamos nas respostas dos entrevistados, principalmente dos egressos, que ainda existe uma visão muito forte da ligação da mulher como a única responsável pelos cuidados, 
com higienização, alimentação, enfim cuidados essenciais esquecendo que cuidamos a todo o momento, não somente quando trocamos ou alimentamos e que o ato de cuidar refere-se também ao principio pedagógico essencial na Educação Infantil.

\section{Considerações finais}

Considerando a temática do presente estudo relativa à atuação de professores homens na Educação Infantil com crianças de 0 a 3 anos, após a realização da pesquisa bibliográfica constatamos que gênero é uma construção social, que muda de acordo com o contexto e que historicamente a área da Educação passou a ser vista como feminina, sendo relacionadas às funções educativas escolares à maternidade.

No caso da Educação Infantil, ela foi idealizada por um homem, Froebel, que já entendia que as pessoas mais aptas para trabalhar como docentes seriam as mulheres, uma vez que elas têm aptidões que são adequadas para o cuidado de crianças. Assim, surge o estereótipo que até hoje persiste de que o homem não seria o mais indicado para trabalhar com bebês, especialmente pelas ações educativas estarem relacionadas à higiene da criança, como trocar e dar banho. Podemos afirmar que esta visão estaria ligada as relações de dominação criadas pela sociedade que influencia no comportamento das pessoas e que contribuiu para o afastamento dos homens da Educação Infantil. Em contrapartida, a LDB e o RCNEI vêm para anular esta corrente de ideais que sinaliza que o homem não serve para trabalhar na Educação Infantil, visto que não mencionam nada relacionado ao gênero do educador, ou que tem que ser homem ou mulher. As publicações do MEC se referem apenas ao processo de formação profissional para atuar na Educação Infantil que, segundo a LDB deve ter formação superior ou magistério e o RCNEI exige um profissional polivalente, capaz de refletir suas práticas, ensinar e aprender com seus alunos.

Quanto às opiniões dos acadêmicos e egressos do curso de Pedagogia, os resultados demonstram o quanto polêmico é este assunto e também apresenta os anseios destes para com a Educação Infantil, lugar que é visto relativamente como feminino o que contribui para a não aceitação de alguns dos participantes. Assim, o que percebemos é que todos os respondentes não tinham o curso de Pedagogia como primeira opção, porém todos gostariam de entrar em cursos de Licenciatura, o que evidenciou o interesse de se tornarem professores de alunos maiores. 
Quanto à atuação de homens com crianças menores de 3 anos de idade, os respondentes divergem em suas opiniões, pois os dois graduandos não pontuam diferenças entre o trabalho feminino e o masculino, porém os egressos acreditam que existem barreiras, para essa atuação, a estranheza dos pais é muito forte no relato dos egressos. Quando mencionam sobre as experiências vividas no estágio, novamente aparecem os pais agindo de forma diferente querendo saber quem são eles e o que fazem ali. Acreditamos serem comuns essas perguntas, visto que não estamos acostumados a ver homens dentro de uma sala de aula da Educação Infantil.

Mediante a realização desse estudo, percebemos que o que mais incomoda os participantes egressos é o cuidar do corpo, como ter que realizar a higiene das crianças, embora os homens que ainda estejam cursando não tenham se referido ao incomodo em dar banho, trocar e alimentar, eles não descartam a hipótese de trabalhar no Ensino Fundamental alegando que a Educação Infantil exige de mais do professor. A diferença que notamos entre os dois grupos pesquisados é que ainda existe uma cultura muito forte em relação ao cuidado da higiene das crianças da Educação Infantil com a mulher, o que fica evidente no relato dos egressos, o banho, a alimentação, a troca de fralda para eles ainda é coisa de mulher, não se dão conta que o cuidado não é só higienizar a criança, cuidamos e educamos o tempo todo.

O olhar desses homens nos leva a refletir sobre o porquê da falta de interesse, e entendemos que não seja por preconceito da comunidade que esta atuação não aconteça, os próprios homens tem enraizados em seus pensamentos a figura da mulher como aquela que leva mais jeito para lidar com crianças principalmente com a faixa etária de 0 a 3 anos, esta relação mulher e maternidade até hoje é presente no cotidiano das pessoas.

Vale ressaltar que o presente artigo não tem o intuito de esgotar a temática uma vez que é importante que novas pesquisas surjam na área afim de melhor compreender a atuação e o interesse do profissional masculino na Educação Infantil, especialmente por se acreditar que homens têm muito a contribuir com o processo educacional de crianças, tanto quanto a mulher o que os coloca em uma posição de igualdade frente ao processo de profissionalização docente.

\section{Referências}

AMUDE, A.M; SILVA, G. B. Os jardins-de-infância: um estudo sobre a formação do ser huma- 
no a partir dos postulados de Friedrich Froebel. Teoria e Prática da Educaçáo, v.11, n.2, maio/ ago., 2008, p.168-172.

ALVES-MAZZOTTI, A.J; GEWANDSZNAJDER, F.O método nas ciências naturais e sociais: pesquisa quantitativa e qualitativa. São Paulo: Pioneira, 1999.

ARAÚJO, P. M.; HAMMES. C. C. A androfobia na educação infantil. Interfaces da Educaçáo. Paranaíba, v. 3, n. 7, 2002, p. 5-20.

BRASIL. MEC. Lei de Diretrizes e Bases da Educaçáo Nacional. Brasília: MEC, 1996. . MEC. Secretaria de Educação Básica. Diretrizes Curriculares Nacionais para a Educaçáo Infantil. Brasília: MEC, SEB, 2010. . Ministério da Educação e do Desporto. Secretaria de Educação Fundamental. Referencial Curricular Nacional para a Educaçáo Infantil / Ministério da Educação e do Desporto, Secretaria de Educação- Brasília: MEC/SEF, 1998.

CARVALHO, M. P .de. Vozes masculinas numa profissão feminina. Revista Estudos Feministas. Florianópolis, v. 06, n. 02, jul/dez., 1998, p. 406-422.

GONÇALVES, J. P. O perfil profissional e representaçóes de bem-estar docente e gênero em homens que tiveram carreiras bem-sucedidas no magistério. 2009. $232 \mathrm{f}$. Tese (Doutorado em Educação) - Pontifícia Universidade Católica do Rio Grande do Sul, PUC/RS, Porto Alegre, 2009.

GRESSLER, L. A. Introdução a pesquisa projetos e relatórios. 3a ed. São Paulo: Loyola, 2007.

LOPES, D. H. Cultura e ralaçóes de Gênero: A Construção dos Papéis masculinos na Escola. Desigualdades e Preconceitos: Reflexôes Sobre Relaçóes Étnico-Raciais e de Gênero na Contemporaneidade. Campo Grande-MS: Editora UFMS. 2012. P.167 a 187.

LOURO, G. L. Mulheres na Sala de Aula. In: PRIORE. M. D.; PINSK. B. C. (Orgs.). Historia das mulheres no Brasil. São Paulo: Contexto, 2012.

MARTINS, A.M. Trajetórias de formação de alunas do curso de pedagogia: uma contribuição ao debate sobre identidade docente. Revista Brasileira de Estudos Pedagógicos. Brasília, v. 90, n. 225, maio/ago. 2009, p. 352-366

MONTENEGRO, T. Educação Infantil: a dimensão moral da função de cuidar. Psicologia da Educaçáo, São Paulo, v. 20, p. 77-101, 2005.

NOVAES, M. E. Professora Primária: Mestra ou Tia. 6a ed. São Paulo: Cortez,1995.

POSSAS, L. M. V; FULFARO, A .C; LOPES, D. H. Gênero na escola: Aprimorando os Conceitos e Discutindo as Praticas. In.: LOPES, Daniel Henrique (Org.). Desigualdades e Preconceitos: Reflexóes Sobre Relaçóes Étnico-Raciais e de Gênero na Contemporaneidade. Campo Grande-MS: Editora UFMS. 2012. p.189 a 206.

SAYÃO, D. Relaçóes de gênero e trabalho docente na educaçáo infantil: um estudo de professores em creche. 2005. 247 f. Tese (Doutorado em Educação) - Programa de Pós-Graduação em Educação, Universidade Federal de Santa Catarina, Santa Catarina. 2005.

Relaçóes de Gênero na Creche os Homens no Cuidado e Educação das Crianças

Pequenas. 2002. Disponível em: http:<<//25reuniao.anped.org.br/tp25.htm\#gt7>> Acesso em: 20 agost 2014 . 
SCOTT, J. Gênero: uma categoria útil de análise histórica. Educação e realidade, Porto Alegre, v. 2, n. 20, p. 71-99, jul./dez. 1998.

RABELO, A. O. Professores discriminados: um estudo sobre os docentes do sexo masculino nas séries do ensino fundamental. Educaçáo e Pesquisa. São Paulo, v. 39, n. 4, p. 907-925 out./dez. 2013. 